\title{
A EXPERIÊNCIA DE UM GRUPO DE PROFESSORES ENVOLVENDO ENSINO DE QUÍMICA E INFORMÁTICA
}

\author{
The experience of a group of teachers involving Chemistry teaching and \\ Information and Communication Technologies (ICT) \\ Wanderlei Sebastião Gabini ${ }^{l}$ \\ Renato Eugênio da Silva Diniz ${ }^{2}$
}

\begin{abstract}
Resumo
Este trabalho teve como objetivo investigar a inserção da informática como estratégia didática para o ensino de Química. Por meio de encontros de um grupo de professores dessa disciplina, foram discutidas experiências já vivenciadas por eles sobre este tema, análise e exploração de softwares, além da elaboração e aplicação de uma proposta de aula na Sala Ambiente de Informática das escolas em que atuavam. Ficou evidente, nesse estudo, a importância de um espaço para o professor discutir sua prática profissional, planejar ações didáticas e conhecer os softwares disponíveis, bem como o fato de a informática ser um recurso viável no ensino de Química.
\end{abstract}

Palavras-chave: Ensino de Química, Informática, Formação de Professores.

\begin{abstract}
The main goal of this work was to investigate the insertion of Information and Communication Technologies (ICT) as strategy for the Chemistry teaching. During the meetings of a teachers' group of this discipline, had been discussed some subjects as the experiences already lived by them about this subject, the analysis and exploration of softwares, besides the elaboration and application of a proposal of class in the Computer lab of the schools where they acted. It was evident, in this study, the importance of a space where the professor can discuss its practical professional, to plan available didactic actions and to know softwares, as well as the fact of Information and Communication Technologies (ICT) being a viable resource in the education of Chemistry.
\end{abstract}

Keywords: Chemistry teaching, Information and Communication Technologies (ICT), teacher education.

\footnotetext{
${ }^{1}$ UNESP: Doutorando do Programa de Pós-Graduação em Educação para a Ciência, Faculdade de Ciências, Campus de Bauru/SP. (wgabini@uol.com.br)

${ }^{2}$ UNESP: Docente do Programa de Pós-Graduação em Educação para a Ciência, Campus de Bauru-SP. (rdiniz@ibb.unesp.br)
} 


\section{INTRODUÇÃO}

As perspectivas do Ensino Médio, que integra a Educação Básica, de acordo com a Lei de Diretrizes e Bases da Educação Nacional (LDBEN), estão voltadas para equipar o aluno-cidadão a atuar frente à vida e ao trabalho. Para que isso seja atingido, como destaca Menezes (2004, p. 22), a proposta é de um "aprendizado ativo e participativo", que dificilmente se articula ao "ensino livresco e ao aprendizado passivo e formal".

Nesse contexto, o conhecimento de Química é parte fundamental na formação do cidadão. A forma como é abordado em muitas realidades, com uma super valorização da memorização de fórmulas e execução de cálculos, sem compreender a sua relação com o conceito que está sendo trabalhado, distancia-o do seu real propósito. Essa situação, que tem relação com a maneira como o processo de ensino e aprendizagem é desenvolvido, pode ser gerada pela preocupação excessiva de se cumprir longos programas de conteúdo, distantes da realidade do aluno, pelo enfoque demasiado no campo submicroscópico e por aulas meramente expositivas. Ações didáticas diversificadas, dentre elas atividades experimentais bem desenvolvidas, a utilização da História da Ciência permeando o andamento das aulas, projetos interdisciplinares e o uso da informática podem, quando articulados, colaborar no propósito de contribuir para a formação de cidadãos comprometidos com sua comunidade. Segundo Chassot (1990, p. 32), “é inadmissível que a Química do $2^{\circ}$ Grau (atual Ensino Médio) não ajude a aperfeiçoar um soldador mecânico, um frentista de posto de combustível, um controlador de alimentos perecíveis de um supermercado, um agricultor, um operário de uma cervejaria, um encanador, um empregado de uma lavanderia". Isso seria, verdadeiramente, educar para a vida e para o trabalho, valendo-se dos conhecimentos de Química.

Cabe ressaltar, entretanto, que apesar de reconhecida a importância do conhecimento científico frente às decisões a serem tomadas no dia-a-dia, a dificuldade de uma concreta articulação entre as realidades descritas é, ainda, bastante evidente. Mortimer (2002, p. 29) destaca que diversas situações do cotidiano, as quais a ciência poderia explicar, são bastante complexas e "envolvem a articulação de vários conceitos científicos, algo a que o professor muitas vezes não está acostumado". Ainda, segundo Mortimer (2000, p. 118), é importante auxiliar os alunos na "construção de algo que é diferente do senso comum". Para ele a elaboração de uma 
"cultura sobre ciência contextualizada na cultura científica" envolve reconhecimento dos limites das teorias, dos modelos e dos avanços.

Para que o verdadeiro papel da Química seja cumprido, o professor é a figura chave. Entretanto, como no curso superior o contato do professor com as novas tecnologias, no caso trabalhado a informática, ainda deixa a desejar, a formação continuada é essencial para suprir essa defasagem. O aprender contínuo é fundamental para a atuação docente, e a criação de espaços para uma prática reflexiva torna possível a revisão da ação do professor. Segundo Nóvoa (1992, p. 26), “a troca de experiências e a partilha de saberes consolidam espaços de formação mútua, nos quais cada professor é chamado a desempenhar, simultaneamente, o papel de formador e de formando".

Um professor reflexivo necessita de um ambiente que propicie essa prática, assim, é necessária uma escola reflexiva, como define Alarcão (2003), que seja um ambiente de interação, onde seus membros enriqueçam-se e qualifiquem-se a si próprios. Segundo Pimenta (2002, p. 45), há que se ter cuidado para a questão de uma "banalização" da idéia de reflexão sobre a prática, julgando que essa prática, sem teoria, seria suficiente para o saber docente. Cursos ensinariam, de forma técnica, o professor a se tornar reflexivo.

A realidade escolar, em tempos de Internet, softwares e outros aplicativos, não deve mais centrar-se apenas em giz e lousa. Essa tecnologia pode, de um lado, colocar o aluno em contato com uma realidade presente no mundo atual e, por outro, eliminar certas discussões, como aponta Ferreiro (2001, p. 25), em torno de questões desnecessárias, como por exemplo, escrever com "letra cursiva ou de imprensa ou usar caracteres separados ou ligados". Ainda, segundo Ferreiro, "a escola não desenvolve a prática nem da busca da informação, nem da tomada de decisões rápidas, da escolha sobre o que é pertinente ou não" (p. 24).

$\mathrm{O}$ erro, frente às inúmeras possibilidades encontradas, passa a fazer parte da busca, e a idéia de experimentação é desenvolvida quando se está diante da tela do computador. O papel do professor é fundamental nesse processo para análise e seleção daquilo que utilizará com os alunos. Os softwares disponíveis e endereços eletrônicos são muitos, mas devem ter um significado para o educando em vez de se transformarem em mero acúmulo de informações.

Segundo Moran (2000, p.53), o uso da Internet pode "ajudar a desenvolver a intuição, a flexibilidade mental, a adaptação a ritmos diferentes". Papert (1994) chama 
de Construcionismo essa possibilidade de construção do conhecimento em que o aluno aprende fazendo e fazendo algo para o qual está motivado.

Levy (2001) aponta que a prática escolar, baseada no "falar/ditar do mestre, na escrita manuscrita do aluno", exige adaptação para a integração da informática, o que não ocorre da noite para o dia. Nesse sentido, aumentam os desafios do professor para encontrar novos caminhos baseados na mediação e na motivação da aprendizagem, porém junto ao desafio há um aumento de possibilidades de geração de situaçõesproblema para o processo de ensino e aprendizagem. Moran (2000) afirma, ainda, que "ensinar com as novas mídias será uma revolução se mudarmos, simultaneamente, os paradigmas convencionais do ensino, que mantêm distantes professores e alunos". Afirma, também, que caso isso não ocorra, teríamos apenas um "verniz de modernidade" que não alteraria a essência do processo desenvolvido na sala de aula.

Para que a implantação da informática no cotidiano escolar seja viabilizada, a formação do professor é fundamental. Valente (1997) alerta para as propostas que muitas vezes são desenvolvidas nos cursos de formação continuada e que são totalmente desarticuladas da situação real em que o professor atua. Aliado a essa questão, o professor pode participar de tais processos de formação continuada e não encontrar "espaço" para desenvolver seu trabalho no ambiente escolar, por diversos motivos, incluindo o da resistência ao novo e às mudanças. Por isso, um espaço para estudo é essencial ao professor, num momento de pós-capacitação, para uma aprendizagem mais efetiva daquilo que vivenciou. Um grupo de professores, quando dispõe desse espaço de estudo, unindo-se em torno de um objetivo comum, trabalha com a ansiedade e o medo, mas desfruta do prazer da descoberta, da construção do conhecimento (Freire, 1992).

Retomando a questão da informática aliada ao ensino de Química, Giordan (1999) aborda as "simulações computacionais", apontando-as como instrumento importante na mediação entre o sujeito, o mundo e o conhecimento. Pode-se lançar mão de inúmeras informações para que uma situação seja reconstituída, como por exemplo, um problema relativo a impacto ambiental, além de se considerar a perspectiva de trabalhar em uma escala tridimensional.

Enfocando-se o Estado de São Paulo, um Programa de Educação Continuada em Informática Educacional, desenvolvido nos anos de 2000, 2001 e 2002, propiciou aos docentes do Ensino Fundamental e Ensino Médio o contato com os softwares disponíveis nas Salas Ambiente de Informática (SAI) e, também, com situações de 
aula envolvendo tais softwares. Há, atualmente, outras propostas da Secretaria da Educação do Estado de São Paulo, focalizando especificamente o uso da SAI.

\section{METODOLOGIA}

A investigação foi desenvolvida com um grupo de professores que lecionava Química em Escolas Públicas Estaduais de São Paulo. O objetivo geral da pesquisa, que direcionou a metodologia utilizada, foi investigar as possibilidades e necessidades referentes à inserção da Informática no Ensino de Química. O contato direto com os professores, junto ao seu ambiente de trabalho, proporcionou que se conseguisse variadas informações sobre essa realidade da prática docente, no que se refere à utilização da Sala Ambiente de Informática. Minayo (1994, p. 54) aponta que, nessa realidade de investigação, consegue-se captar o que "há de mais imponderável e evasivo na vida real".

O trabalho foi desenvolvido num período de oito meses, com encontros quinzenais, de uma hora de duração. Inicialmente, foi feito um contato com os professores e direção das escolas escolhidas para viabilização desses encontros. Numa etapa seguinte, realizaram-se tais encontros, registrados em fita de áudio, com posterior transcrição. Na seqüência, o grupo desenvolveu as aulas nas SAIs das escolas, com alunos da $1^{\text {a }}$ série do Ensino Médio, utilizando um software ali disponível, que trata, entre outros temas, de estrutura atômica. Essas aulas foram gravadas em vídeo, sendo que, posteriormente, houve um encontro individual com cada professor, registrado em fita de áudio e encontros em grupo, até o final do ano de 2003.

A partir da coleta de dados, buscou-se relacionar tais dados ao propósito da pesquisa, estabelecido inicialmente. Nos encontros, procurou-se perceber o ponto de vista dos professores sobre a questão do uso da informática no ensino de Química, criando condições para que refletissem sobre sua prática, frente à tecnologia disponível. Buscou-se garantir que os professores conhecessem os softwares de que dispunham para as suas aulas e que a proposta de roteiro de aula fosse, de fato, desenvolvida pelo grupo, discutindo-se em conjunto a opção que melhor julgassem atender às expectativas para essas aulas. 


\section{RESULTADOS E DISCUSSÃO}

A partir da caracterização do grupo, obtida com a análise de um questionário inicial, ficou evidente sua heterogeneidade em diversos aspectos, tais como a formação inicial e continuada, tempo de magistério, carga horária de trabalho e situação funcional. As expectativas do grupo localizavam-se, inicialmente, em resultados mais imediatos quanto à utilização da sala de Informática.

Os encontros revelaram que a vivência dos professores em relação ao contato com os softwares, disponíveis na Sala de Informática, e sua utilização era bastante diversa. Houve, então, a preocupação em garantir esse contato do professor com a navegação pelos softwares e com o conteúdo possível de ser trabalhado. No decorrer das discussões, da troca de experiências e da exploração dos softwares, o grupo passou a elaborar um roteiro para o desenvolvimento de algumas aulas na Sala Ambiente de Informática, utilizando tais recursos. Alguns aspectos a respeito dos softwares foram sendo percebidos e alguns pontos falhos, quanto ao seu funcionamento, detectados pelos professores. Esse foi um detalhe importante, pois softwares apresentam pontos negativos, que não podem ser ignorados ou deixados de lado para o desenvolvimento das aulas, e uma visão crítica do professor sobre eles é fundamental.

Posteriormente, concluído o roteiro, o grupo decidiu que a aplicação seria desenvolvida pelos professores em situações diferentes. Em alguns momentos o trabalho seria feito com todos os alunos da sala e, em outros, com parte deles, o que serviria para simular as situações discutidas e levantadas durante os encontros (salas com mais ou menos alunos). Essas aulas aconteceram em duas das três escolas cujos professores participavam do grupo. A terceira escola estava passando por reforma naquele momento e, apenas no final do ano, os professores ali atuaram, porém sem registro em vídeo.

Após a realização das aulas, em encontros individuais com os professores, abordou-se o andamento de cada uma (pontos positivos ou dificuldades), o desempenho dos alunos, o número de alunos por turma, problemas com o software, o roteiro e o tempo. Os professores foram também questionados em relação ao grupo de estudos.

Alguns comentários a respeito dessas questões são destacados a seguir. Salientamos que os nomes atribuídos aos docentes são fictícios. 
"Foi uma aula diferente e isso estimulou eles a participarem." (Profa Luíza, a respeito do andamento da aula);

"Um pouco de dificuldade para estar mexendo ali. Muitas vezes iam no lugar errado e não sabiam voltar." (Prof. Luis, sobre o desempenho dos alunos);

"O roteiro é fundamental. Talvez a gente sobrecarregou, ficou um pouco repetitivo alguns exercícios." (Profa Márcia, a respeito de problemas com o roteiro);

"Eu acho que em muitas salas dá certo, mesmo com número grande de alunos." (Profa Luíza, sobre o número de alunos por turma);

"A gente se encontrando, discutindo antes, é outra base que a gente vai para a sala para fazer a atividade." (Profa Solange, a respeito do grupo de estudos);

"No grupo a gente troca idéias, vamos fazer assim, vamos fazer assado." (Prof. Pedro, a respeito do grupo de estudos).

Os alunos receberam o roteiro juntamente com uma avaliação a ser feita sobre a aula, que abordava pontos positivos, pontos negativos, dificuldades encontradas, aprendizagem e sugestões. Quase a totalidade das avaliações trouxe como sugestão a continuidade das aulas na SAI, estendendo-as a outras disciplinas. Os aspectos negativos e dificuldades foram pouco destacados.

Em continuidade aos encontros, após esse trabalho com as aulas, um outro aspecto merece ser salientado: dois professores do grupo estavam desenvolvendo atividades independentemente do roteiro que havia sido utilizado. Uma professora, inclusive, criou um roteiro próprio, para outro assunto e outra série, discutindo com o grupo os resultados de seu trabalho. Nessa discussão, a professora Márcia colocou:

“O jeito que eu preparei não ficou atrativo para eles; faltou alguma coisa, melhorar ou tirar... acho que eu perguntei muito; obriguei muito eles a procurarem no texto, sabe ..." 
Um aspecto marcante observado refere-se à insegurança e ao medo, presentes nos professores em relação ao uso da sala de informática, como nos registros seguintes:

“Na teoria deve funcionar bem.” (Profa Luiza);

"Eu tenho medo. Já pensei milhões de vezes nisso... medo de não conseguir. Você vê que aquele está te chamando pra explicar, enquanto o outro está berrando, querendo falar do outro lá. Então eu fico apavorada de pensar. Fico nervosa, fico pensando lá, sem o auxílio de ninguém...” (Profa Márcia).

A professora Márcia, em um dos últimos encontros, manifestou uma posição que, ao ser confrontada com o pessimismo inicial que demonstrara, tornou-se ponto marcante.

"Eu acho que o futuro é isso aí mesmo. Eu acho que agora eu me sinto mais preparada pra mergulhar mais e preparar, melhorar."

Além disso, essa mesma professora sinalizou a respeito do aspecto social, acrescido ao educacional, na utilização dessa tecnologia.

“Uma coisa que eu falei ... barra de rolagem ... parecia que estava falando um palavrão."

Possivelmente, para muitos alunos, a oportunidade de contato com o computador seja unicamente através da escola. Não se pode, portanto, furtar desse aluno a possibilidade de inserção social, valendo-se de habilidades conquistadas com o uso de novas ferramentas.

Outro ponto a ser ressaltado, levantado durante as reuniões do grupo, é a informática como um recurso a mais para a mediação com o aluno, como aponta Giordan (1999). Não se está desconsiderando, por exemplo, a importância marcante das atividades experimentais, pois em muitos casos pode-se associar, em determinados tópicos, as atividades experimentais e o uso da informática. Foi levantado em uma das reuniões que uma atividade experimental, por exemplo, onde exista a liberação de gás, 
o software poderia estar simulando, ilustradamente, o resultado dessa reação. A atividade prática poderia utilizar uma bexiga para coletar esse gás, complementando a simulação no computador.

Questões interessantes emergiram dentro do grupo, o que reforçou a idéia de que a troca de experiências é bastante produtiva, sobretudo quando estão em contato pessoas que têm formação de licenciatura em Química e outros com licenciaturas na área, mas que lecionam Química. Esse é um espaço de incentivo para que o professor, enquanto estudioso da disciplina que ministra, possa adquirir e, se for o caso, reorganizar os conteúdos que desenvolve. É também espaço para que o professor recém-formado, que não teve contato no curso de graduação com o uso de novas tecnologias, familiarize-se com aquilo de que dispõe para desenvolver suas aulas. Muitas vezes, na formação inicial do professor, essa falha pode criar um dificultador para o uso dessas tecnologias em sua prática docente.

\section{CONSIDERAÇÕES FINAIS}

Algumas questões gerais foram lançadas, inicialmente, para guiar o desenvolvimento da pesquisa. Essas questões foram: a escola está preparada para o uso da informática no ensino? O professor está preparado para incorporar o uso do computador na sua prática? A criação de espaços para que o professor possa refletir sobre a questão trará conseqüências favoráveis? O trabalho com o recurso da informática é produtivo para o ensino de Química?

Com os dados coletados e as discussões ocorridas, concluiu-se que o uso da sala de informática não é uma prática comum no cotidiano escolar, mesmo após o desenvolvimento de cursos pelo PEC Informática Educacional. A utilização dos softwares como parte da proposta pedagógica da escola, realmente incorporada como uma prática efetiva do trabalho docente, contribui para a alteração dessa realidade. Problemas de operacionalização, como um dos softwares se apresentar em inglês, podem gerar barreiras para um uso mais adequado.

O professor, sem conhecer o conteúdo desses softwares e sem dominar sua "navegação", não pode fazer um uso adequado dos mesmos em sua ação docente. Para conhecer tal material, além dos cursos já citados, há necessidade de garantia de tempo para estudo. O espaço de HTPC (Hora de Trabalho Pedagógico Coletivo) poderia incorporar uma prática de estudo e discussão para esses softwares. A formação 
continuada é de extrema importância para suprir a deficiência desse contato com a informática educacional na graduação, pois muitas escolas têm alterações acentuadas no quadro docente anualmente e muitos professores que chegam à unidade escolar desconhecem tais recursos.

Para a Química não é comum encontrar oportunidades de grupos estruturados de professores para discutir sua prática docente. Talvez eles existam em regiões próximas a Faculdades ou Universidades que mantêm cursos de formação de professores na disciplina. Com o amadurecimento das discussões em grupos de estudos, alguns aspectos podem ser destacados como, por exemplo: a realidade do professor servindo de base para as discussões; a percepção de que dificuldades existem, de que cada escola é uma escola, mas que é possível desenvolver um trabalho com maior qualidade e compromisso; o professor mais aberto a mudanças em sua prática quando percebe resultados positivos acontecendo com outros colegas, possibilitando a melhoria em situações de insegurança para o uso da SAI.

O grupo, contudo, apresentou limites. Tais limites estão relacionados à percepção de pontos falhos nas aulas desenvolvidas, à viabilização de novas atividades independentes daquelas propostas pelo grupo e às concepções enraizadas, que demandam tempo e prática para serem alteradas.

O planejamento da aula a ser executada na Sala de Informática é muito importante. Isso leva à modificação de uma atitude comumente encontrada, na qual o professor tende a esperar "receitas prontas" que se adaptem e resolvam todas as suas dificuldades e aspirações. No caso da atividade elaborada pelos professores desse grupo, o objetivo proposto foi bastante "pesado" para uma aula. Esse objetivo, se bem delimitado, orienta melhor o trabalho do professor.

Focalizando as atividades do ensino de Ciências, o uso do computador pode mobilizar ações dos alunos, de forma a potencializar a resolução de problemas e, conseqüentemente, favorecer o desencadeamento dos processos cognitivos. Também a simulação de experimentos, tornando possível o controle de variáveis, a visualização e a animação permitem ao educando uma interação mais elaborada com processos e fenômenos que ocorrem em um nível submicroscópico, fornecendo elementos que possibilitem uma aprendizagem significativa dos conhecimentos científicos estudados. Um outro aspecto a ser exemplificado é o trabalho dos alunos em duplas nos computadores, que favorece as trocas e interações e possibilita uma compreensão mais efetiva dos conteúdos. 
Além da simulação de experimentos, os softwares oferecem a possibilidade de estudo, pesquisa e do desenvolvimento de projetos interdisciplinares. Na avaliação realizada pelos alunos, o uso da informática para o ensino de Química é visto como um ponto que desperta maior interesse nas aulas.

Vale ressaltar que essa discussão não pode ocorrer isolada do coletivo da escola, senão o espaço da Sala Ambiente de Informática não proporcionará a quebra na realidade do giz e lousa, que ainda impera no cotidiano de muitas escolas nos dias atuais.

\section{REFERÊNCIAS BIBLIOGRÁFICAS}

ALARCÃO, I. Professores reflexivos em uma escola reflexiva, $2^{a}$ edição. São Paulo: Cortez, 2003.

BRASIL. Lei 9394, 20 dez. 1996. Estabelece as Diretrizes e Bases da Educação Nacional.

CHASSOT, A. I. A Educação no Ensino de Química. Ijuí: Livraria Unijuí Editora, 1990.

FERREIRO, E. Computador Muda Práticas de Leitura e Escrita. Revista de Educação e Informática - Acesso. FDE/GIP, № 15, São Paulo, p.23-25, dez. 2001.

FREIRE, M. O que é um grupo? In: GROSSI, E. P.; BORDIN, J. (Orgs) Paixão de Aprender. Petrópolis: Vozes, 1992.

GIORDAN, M. O Papel da Experimentação no Ensino de Ciências. Química Nova na Escola. SBQ, No 10, p.43-49, nov. 1999.

LÉVY, P. As Tecnologias da Inteligência: o futuro do pensamento na era da informática. Trad. Carlos Irineu da Costa. Rio de Janeiro: Editora 34, 1993.

MENEZES, L. C. A Ciência como Linguagem - Prioridades no Currículo do Ensino Médio. In: O Currículo na Escola Média: Desafios e Perspectivas. São Paulo. CENP/SEE. 2004.

MINAYO, M. C. S. Ciência, Técnica e Arte: O Desafio da Pesquisa Social. In: MINAYO, M. C. S. (Org) Pesquisa Social - Teoria, Método e Criatividade, 21 ${ }^{\mathrm{a}}$ edição. Petrópolis: Vozes, 2002.

MORAN, J. M.; MASETTO, M. T.; BEHRENS, M. A. Novas Tecnologias $e$ Mediação Pedagógica, $7^{\mathrm{a}}$ edição. Campinas: Papirus, 2003. 
MORTIMER, E. F. Linguagem e Formação de Conceitos no Ensino de Ciências. Belo Horizonte: Editora UFMG, 2000.

MORTIMER, E. F. Uma Agenda para a Pesquisa em Educação em Ciências. Revista Brasileira de Pesquisa em Educação em Ciências, v.2, n.1, jan./abr. 2002. Disponível em: <http://www.fc.unesp.br/abrapec/revistas/v2n1a2.pdf> . Acesso em: 26 jul. 2005.

NÓVOA, A. Formação de Professores e Profissão Docente. In: NÓVOA, A. (Org.) Os Professores e a sua Formação. Lisboa: Dom Quixote - Nova Enciclopédia, 1992.

PAPERT, S. A Máquina das Crianças - Repensando a Escola na Era da Informática. Trad. Sandra Costa. Porto Alegre: Artes Médicas, 1994.

PIMENTA, S. G. Professor Reflexivo: Construindo uma Crítica. In: PIMENTA, S. G.; GHEDIN, E. (Orgs.) Professor Reflexivo no Brasil - Gênese e Crítica de um Conceito, 2a edição. São Paulo: Cortez, 2002.

VALENTE, J. A.; ALMEIDA, F. J. Visão Analítica da Informática na Educação no Brasil: a questão da formação do professor. Revista Brasileira de Informática na Educação, n.1, set. 1997. Disponível em: <http://www.inf.ufsc.br/sbc-ie/revista/nr1>. Acesso em: 6 jul. 2004. 